\title{
Commentary: Is more always better?
}

\author{
Steven L. Lansman, MD, PhD
}

From the Westchester Medical Center, Valhalla, NY; and Section of Cardiothoracic Surgery, Department of Surgery, New York Medical College, Valhalla, NY.

Disclosures: Author has nothing to disclose with regard to commercial support.

Received for publication Dec 10, 2018; accepted for publication Dec 10, 2018; available ahead of print Jan 11, 2019.

Address for reprints: Steven L. Lansman, MD, PhD, 100 Woods Rd, Macy Pavilion, 114W, Valhalla, NY 10595 (E-mail: Steven.Lansman@WMCHealth.org).

J Thorac Cardiovasc Surg 2019;158:1282

$0022-5223 / \$ 36.00$

Copyright (c) 2018 by The American Association for Thoracic Surgery

https://doi.org/10.1016/j.jtcvs.2018.12.030

Current discussion regarding the best management of acute type A aortic dissection is focused on whether to perform a standard hemiarch resection or an extended repair in hopes of improving long-term outcomes by avoiding late distal aortic sequelae. Critical to this discussion is an estimation of the short-term risks of an extended procedure and the magnitude of the late "downstream problem." The article by Preventza and colleagues ${ }^{1}$ is a well-documented report from an experienced center that adds important information to the discussion - a weighty institution weighing in.

First, this report represents follow-up of a large experience: 178 cases, with 63 hemiarch/frozen elephant trunk cases. Of note, several aspects of this report distinguish it from most articles on this topic: (1) The series includes only DeBakey type I cases, an important issue, because hemiarch should be curative for DeBakey II cases. (2) Whereas many reports show that extending the hemiarch operation significantly adds to hypothermic circulatory arrest and selective cerebral perfusion time, in this study, deploying the stent took only 5 minutes extra over the standard procedure. (3) Surgeon bias regarding which patients underwent a frozen elephant trunk confounds most reports, whereas propensity score analysis addresses that issue in this article.

Although this is a well-conducted study from an expert team, with expert statistical analysis, it is counterintuitive that propensity-matched operative mortality in the standard group, which is toward the high end of reported mortalities for hemiarch, is higher than that for the more complex operation, which is at the low end of reports for hemiarch. One cannot avoid wondering whether, despite propensity matching, smart, talented surgeons knew which patients would tolerate the extended procedure.

A review of the literature suggests that extending the classic hemiarch repair for acute type A aortic dissection may decrease late aortic events but does not improve

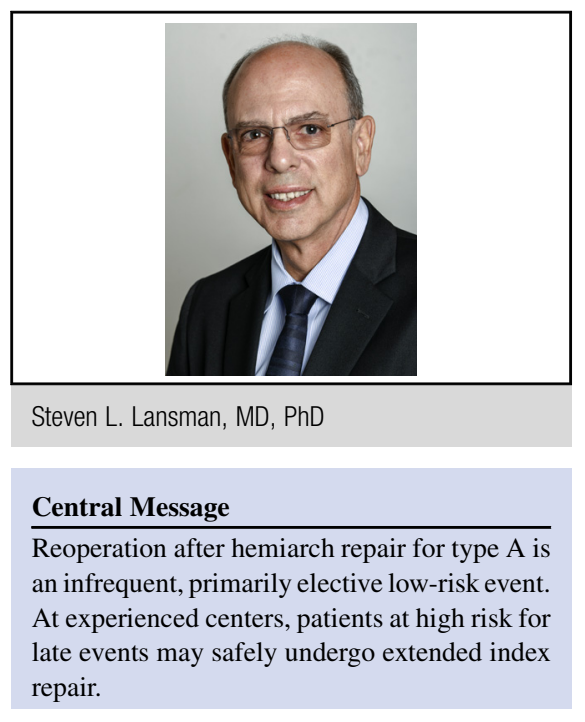

See Article page 1273 .

survival and may carry some increased perioperative risk, not the least of which is paraplegia. The most common late event is reoperation on the distal aorta; however, extended procedures do not eliminate late reoperations, and it is unclear whether, or to what extent, they reduce the incidence of reoperations. Moreover, late reoperations are low-frequency, primarily elective, low-risk events. ${ }^{2}$ Routine extension of the index procedure puts $100 \%$ of patients at risk to protect the minority who may benefit.

In the hands of this experienced group, operative mortality $(12.7 \%)$ and paraplegia $(1.6 \%)$ rates were low. As devices improve and centers can reliably reproduce such excellent outcomes, the extended repair for type A dissection may become a reasonable alternative for patients who are at high risk of developing downstream problems.

\section{References}

1. Preventza O, Olive JK, Liao JL, Orozco-Sevilla V, Simpson K, Rodriguez MR, et al. Acute type I aortic dissection with or without antegrade stent delivery: mid-term outcomes. J Thorac Cardiovasc Surg. 2019;158:1273-81.

2. Lansman SL, Goldberg JB, Kai M, Malekan R, Spielvogel D. Extended arch procedures for acute type A aortic dissection: a downstream problem? Semin Thorac Cardiovasc Surg. August 3, 2018 [Epub ahead of print]. 